\title{
Niveles de anticuerpos vacunales contra enfermedad de Gumboro en pollitos parrilleros a los 21 y 28 días post-nacimiento
}

\author{
Presentado, G. ; Caballero, J.G. ${ }^{2}$; Álvarez, F.L. ${ }^{2}$; Vergara, O.D. ${ }^{2}$; Álvarez, R. ${ }^{3}$ \\ ${ }^{1}$ Cátedra de Epidemiología, ${ }^{2}$ Cátedra de Patología y Clínica Aviar, ${ }^{3}$ Departamento de Investigación Científica \\ y Tecnológica, Facultad de Ciencias Veterinarias, Universidad Nacional de Asunción, San Lorenzo, Paraguay. \\ E-mail: gpresentado@vet.una.py
}

\begin{abstract}
Resumen
Presentado, G.; Caballero, J.G.; Álvarez, F.L.; Vergara, O.D.; Álvarez, R.: Niveles de anticuerpos a los 21 y 28 días de edad post-vacunación contra enfermedad de Gumboro en pollos parrilleros. Rev. vet. 29: 2, 119-122, 2018. La bursitis infecciosa aguda, conocida como enfermedad de Gumboro, es una afección viral muy contagiosa, económicamente importante por afectar severamente a los pollos producidos comercialmente en el mundo entero. El objetivo del trabajo fue comparar, a los 21 y 28 días de edad, los niveles de anticuerpos post-vacunales contra dicha enfermedad en pollos parrilleros inoculados con vacuna recombinante in ovo a los 18 días en planta de incubación, así como medir los niveles de anticuerpos a los $1,7,14,21,28$ y 35 días de edad a fin de trazar la curva de anticuerpos post-vacunales. De una población total de 200 pollitos parrilleros, 28 fueron seleccionados al azar para la extracción de sangre, que se realizó por punción cardiaca a los 1, 7 y 14 días de edad, así como por punción de la vena alar a los 21, 28 y 35 días de edad. Las muestras fueron procesadas mediante el método ELISA indirecto, utilizándose un kit comercial (Idexx Lab). Los resultados correspondientes a los títulos geométricos promedio de anticuerpos fueron: día 1: 6955, día 7: 3678, día 14: 808 , día 21: 34, día 28: 8, y día 35: 3013. No se encontraron diferencias estadísticamente significativas $(p>0,05)$ en los niveles de anticuerpos entre los días 21 y 28 , siendo los mismos considerados como no protectivos.
\end{abstract}

Palabras clave: pollos parrilleros, enfermedad de Gumboro, vacunas recombinantes, anticuerpos post-vacunales.

\begin{abstract}
Presentado, G.; Caballero, J.G.; Álvarez, F.L.; Vergara, O.D.; Álvarez, R.: Levels of vaccinal antibodies against Gumboro disease in 21 and 28 post-birth day broiler chickens. Rev. vet. 29: 2, 119-122, 2018. The infectious bursal disease virus is the etiological agent of the acute and highly contagious infectious bursal disease (IBD) or "Gumboro disease". IBD is one of the most important diseases that affect poultry farming worldwide. The aim of this study was to determine the levels of antibodies after vaccination against IBD in broilers with recombinant vaccine in ovo at 18 days. From a total of 200 birds, 28 animals were randomly sampled. Blood was collected by cardiac puncture at 1, 7 and 14 days-old and by vein puncture at 21, 28 and 35 days-old. Samples were analyzed by means of enzyme-linked immunosorbent assay (ELISA) indirect method, using a commercial kit (Idexx Lab). Results showed that the average antibody levels/titles were: $6955,3678,808,34,8$, and 3013 , for days $1,7,14,21,28$ and 35 days, respectively. No statistically significant differences $(p>0,05)$ in the levels of antibodies between 21 and 28 days were observed, thus considering immune proteins as non-protective.
\end{abstract}

Key words: broilers, Gumboro disease, recombinant vaccine, antibodies after vaccination.

\section{INTRODUCCIÓN}

A nivel mundial, la industria avícola es una de las que más ha crecido en los últimos años, razón por la cual se ha intensificado la producción de pollos parrilleros de acuerdo a la demanda del mercado, siendo uno de los motivos la tendencia de alza en los precios ostentada por la carne bovina.

En Paraguay, el stock de pollos parrilleros ha crecido notablemente, hecho que puede evidenciarse en el incremento sostenido de la faena: en el año 2002 se consumieron más de 15 millones de pollos, cifra que en 2013 ascendió a $56.840 .626^{14}$. 
La intensificación de la producción avícola trae consigo mayor número de granjas, hacinamiento de aves y -por ende- mayores riesgos desde el punto de vista sanitario, tornando ineludible la consideración de la inmunidad del lote, ya que una respuesta inmune deficiente inducirá siempre al incremento de las pérdidas por enfermedades.

En este contexto, desde el punto de vista epidemiológico, la enfermedad de Gumboro (IBG) desarrolla actualmente un papel importante como factor negativo en la producción e industria avícola, ya que su carácter inmunosupresor hace que las aves se vean expuestas a diferentes enfermedades, afectando su rendimiento productivo.

La IBG es causada por un virus altamente contagioso, el cual se presenta con preferencia en aves jóvenes, afectando al sistema inmunológico especialmente a nivel de la bolsa de Fabricio, siendo al parecer el órgano blanco primario del virus, que provoca una inmunosupresión. Para el diagnóstico es importante que al examinar las aves se tenga en cuenta la secuencia de las alteraciones, ya que luego de los daños en la citada glándula se han descripto lesiones a nivel de riñón e hígado. Teniendo en cuenta la inmunosupresión causada, esta virosis representa una amenaza permanente para la industria avícola, considerando las repercusiones en el rendimiento productivo de los planteles avícolas $1,11,12,13$.

La enfermedad es de distribución mundial, con mayor incidencia en las grandes áreas de producción avícola; es altamente contagiosa y afecta a los pollos hasta las 6 semanas de edad, causando morbilidad que puede llegar al 100\% y mortalidad de hasta el 30\%.

La forma subclínica es la más importante, presentándose en aves hasta las 3 semanas de edad. Aunque no ostenta signos clínicos evidentes, se caracteriza por una severa inmunodepresión que conlleva a la aparición de otras enfermedades. La forma clínica se observa en aves mayores de 3 semanas de edad, con aparición súbita y mortalidad elevada, que ocurre a los 5 a 7 días post-infección y se caracteriza por diarrea, decaimiento y deshidratación, seguida de una rápida recuperación de los sobrevivientes ${ }^{10}$.

Acorde a las pérdidas económicas que puede generar, es considerada una de las enfermedades de mayor importancia para la avicultura en el mundo, ya que no solo cursa en la forma clínica con mortalidad elevada, sino por su efecto inmunosupresor sobre todo en pollos menores de 3 semanas de edad ${ }^{15}$.

Como medidas de prevención ante esta enfermedad se cuenta con programas de vacunación, en los cuales se utilizan diferentes tipos de vacunas, dependiendo de diversos factores tales como condiciones de manejo, lote de aves, tipo de producción, prevalencia a nivel local y disponibilidad de productos para inmunización, entre otros.

Teniendo en cuenta la diversidad de factores a tener en cuenta para la instauración de programas de vacunación, se realizaron distintos estudios sobre la determinación de niveles de anticuerpos en pollitos. Así, en una investigación realizada en Cuba con el objetivo de determinar la vida media de anticuerpos contra IBG en pollitos sin vacunar, se obtuvo un resultado de 7,5 días $^{9}$.

Una de las nuevas alternativas que está siendo utilizada a nivel mundial es la implementación de vacunas recombinantes, cuya aplicación puede ser realizada in ovo en planta de incubación o en forma subcutánea a los 2 días de edad.

En tal sentido, investigadores locales han observado que los niveles de anticuerpos promedio han sido considerados como no protectivos en los 14, 21, 28 y 35 días posteriores a la vacunación, ya que presentaron títulos promedio de anticuerpos (en densidad óptica) de 371,132 y 324 respectivamente, utilizando vacunas recombinantes aplicadas in ovo en planta de producción ${ }^{6}$.

Esta investigación se planteó teniendo en cuenta que en Paraguay se encontraron escasos estudios de rigor científico utilizando vacunas recombinantes, y que la IBG continúa siendo un problema de sanidad en las aves por su alta morbilidad, el difícil control de la movilización de animales y la deficiente bioseguridad en las explotaciones avícolas del país.

El objetivo del presente trabajo fue determinar los niveles de anticuerpos post-vacunales generados por un inmunógeno recombinante contra la enfermedad de Gumboro en pollos parrilleros a los 21 y 28 días de edad. También se incluyó la medición de los niveles de anticuerpos post-vacunales a los días 1, 7, 14, 21, 28 y 35 a fin de trazar la correspondiente curva de anticuerpos post-vacunales.

\section{MATERIAL Y MÉTODOS}

Previo acondicionamiento del galpón se procedió a la recepción de 200 pollitos parrilleros provenientes de una planta de incubación, inoculados con una vacuna recombinante in ovo a los 18 días, a dosis de $0,05 \mathrm{ml}$ por huevo embrionado. Dicha vacuna fue producida con la cepa del herpesvirus de pavo (HVT), que expresa el antígeno protector (VP2) del virus de la bursitis infecciosa aviar (IBDV) cepa Faragher 52/70. Estos huevos inoculados provenían de reproductoras de diferentes edades.

Los pollitos fueron ubicados en boxes dentro de un círculo protector e identificados con pintura sintética en el dorso, con colores diferentes de acuerdo a cada lote. Al azar fueron seleccionados 28 pollitos. Las muestras de sangre fueron extraídas del corazón en los pollitos de 1, 7 y 14 días de edad y por venopunción para los animales de 21, 28 y 35 días de edad.

Para la determinación del título de anticuerpos fue utilizado un kit comercial que consiste en un ensayo de inmunoabsorción ligado a enzimas (ELISA, Iddex), del tipo indirecto. Para la lectura del título de anticuerpos se utilizo un software Lineal Flock Check. Según la escala del kit comercial fueron considerados como títulos protectivos los niveles de anticuerpos a partir de 396 títulos de anticuerpos, teniéndose en cuenta ade- 
más de los títulos promedio de anticuerpos, su desvío estándar ${ }^{7}$.

Fueron utilizados los resultados obtenidos de los títulos promedio de anticuerpos en los días 21 y 28 , teniendo en cuenta que los pollitos son más susceptibles a la enfermedad en el mencionado período de tiempo. Posteriormente se clasificaron en protectivos y no protectivos $(<396$ títulos promedio) y finalmente fueron sometidos al estadístico chi cuadrado con un nivel de confianza del 95\% $(\mathrm{p}<0,05)$, empleando el software Epidat (versión 3.1).

\section{RESULTADOS Y DISCUSIÓN}

En la Figura 1 se observan los títulos promedio de anticuerpos a fin de trazar la curva inmunitaria, de acuerdo a los diferentes días en los que fue realizada la toma de muestras, los mismos representan los promedios correspondientes a los 28 pollitos. Se evidencia que los mayores títulos promedio ocurrieron en el día 1 (6955) y día 7 (3678), considerándose los mismos como protectivos de acuerdo a la escala del kit comercial utilizado.

En los días 14, 21 y 28 los títulos promedio descendieron gradualmente y fueron considerados no protectivos, ya que se encontraron por debajo de 396 títulos promedio de anticuerpos. Posteriormente, el llamativo aumento a los 35 días con un nivel de 3013, fue considerado protectivo. No se observaron diferencias estadísticamente significativas $(\mathrm{p}>0,05)$ en los títulos promedio de anticuerpos en los días 21 y 28.

El aumento del título de anticuerpo a los 35 días, podría haberse debido a una respuesta del sistema inmune ante la presencia del virus, aunque no se observaron manifestaciones clínicas de IBG ni resultados laboratoriales que respalden esta hipótesis.

Investigadores colombianos evaluaron el catabolismo de anticuerpos maternos y su interacción con tres planes vacunales, evidenciando un catabolismo de anticuerpos entre los 21 y 28 días, resaltando que en los grupos vacunados no se presentó una respuesta inmune activa frente a ningún plan de vacunación ${ }^{3}$.

Los descensos de títulos de anticuerpos registrados en el presente trabajo desde el día 1 hasta los 28 días de edad, podrían deberse al catabolismo normal de los anticuerpos maternales, aunque no se descarta la posibilidad que exista un fenómeno de neutralización entre los anticuerpos maternales y los post-vacunales generados por el organismo, ya que la vacunación fue realizada utilizando una vacuna recombinante in ovo. Cabe destacar que, con el kit comercial ELISA utilizado no es posible la diferenciación de anticuerpos maternales y anticuerpos post-vacunales ${ }^{2}$.

Nuestros hallazgos resultaron similares a los reportados por investigadores españoles ${ }^{8}$, quienes evaluaron los niveles de anticuerpos con dos tipos diferentes de kits ELISA, utilizando vacuna recombinante. Así, se comprobaron niveles de anticuer-

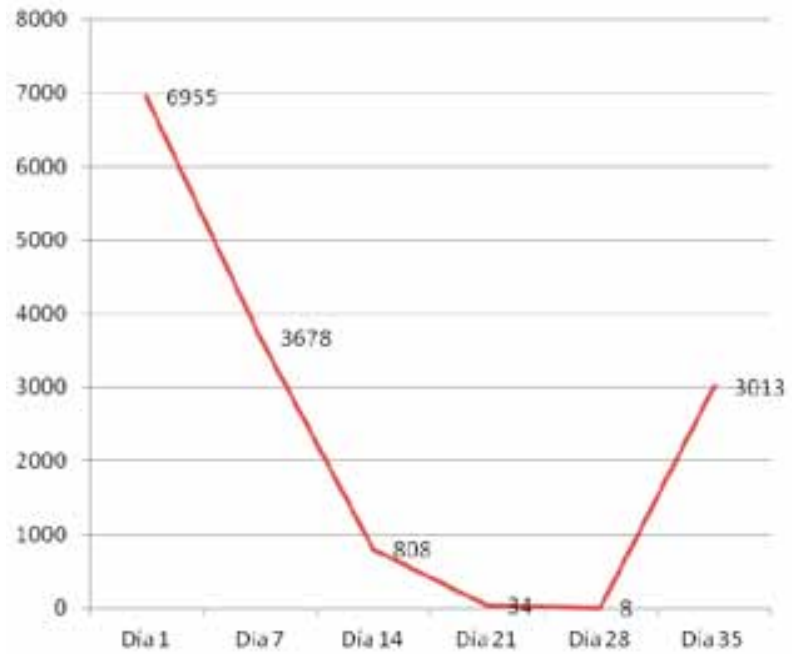

Figura 1. Título promedio de anticuerpos según día de muestreo.

pos bajos en los días 21 y 28 con la utilización de un kit de ELISA clásico para la detección de anticuerpos contra IBG, evidenciándose que no existió un desafío de campo.

Sin embargo, con el kit ELISA específico utilizado en el mismo estudio, se comprobaron niveles protectivos de anticuerpos en los días 21 y 28. La diferencia encontrada radica en la sensibilidad de los kits utilizados en ese estudio. El kit ELISA específico es desarrollado con antígeno recubierto proveniente de una cepa clásica de bursitis natal y no de una cepa clásica crecida en cultivo de tejidos.

Además, los resultados obtenidos en un trabajo realizado en Paraguay coinciden parcialmente con los obtenidos en esta investigación ${ }^{6}$. En aquél estudio se obtuvieron títulos promedio de anticuerpos no protectivos en los días 21 y 28 respectivamente utilizando un kit ELISA clásico, por lo que se demostró que tampoco se presentó un desafío a campo. La diferencia radica en que nuestro muestreo valoró niveles de anticuerpos hasta los 35 días de edad, registrándose un aumento considerable del título de anticuerpos a la mencionada edad.

Los resultados del presente trabajo concuerdan parcialmente con los publicados por otros autores ${ }^{4}$, quienes valoraron los niveles de anticuerpos conferidos utilizando dos cepas intermedias de vacunas contra IBG. Ellos reportaron que aves vacunadas a los 19 días de edad presentaron niveles de anticuerpos no protectivos en los días 19 y 26, pero a los 35 días de edad observaron niveles de anticuerpos de 8980 y 7844 respectivamente, lo cual indica una sólida respuesta inmunológica, en contraposición a lo obtenido en este estudio.

Tabla 1. Promedios, desvíos estándares y coeficientes de variación de la curva inmunitaria.

\begin{tabular}{lcccccc}
\hline estadísticas & día 1 & día 7 & día 14 & día 21 & día 28 & día 35 \\
\hline valor promedio & 6955 & 3678 & 808 & 34 & 8 & 3013 \\
desvío estándar & 2354 & 1290 & 326 & 62 & 30 & 1288 \\
coeficiente variación & 34 & 35 & 40 & 183 & 366 & 43 \\
\hline
\end{tabular}


Como indica la Tabla 1, los coeficientes de variación de los títulos de anticuerpos de lotes oscilaron entre un 34 y 43\% para los 1, 7, 14 y 35 días respectivamente. Estos coeficientes de variación indican que las muestras podrían ser denominadas como no homogéneas ya que para muestras biológicas son consideradas homogéneas aquellas cuyos coeficientes de variación no superen el $30 \%{ }^{5}$. La variabilidad encontrada en el estudio podría deberse a que las aves provenían de matrices con edades diferentes. No se han tenido en cuenta para el análisis los coeficientes de variación de los 21 y 28 días, ya que los títulos de anticuerpos obtenidos en los mismos han sido considerados como no protectivos.

En conclusión, con el kit ELISA utilizado no se han detectado niveles de anticuerpos considerados como protectivos entre los 21 y 28 días de sangrado en las aves en estudio. El aumento del título promedio de anticuerpos a los 35 días, podría haberse debido a una respuesta del sistema inmune ante la presencia del virus, aunque no se observaron manifestaciones clínicas de IBG ni resultados laboratoriales que respalden esta hipótesis.

Es aconsejable seguir realizando estudios serológicos de IBG con diferentes tipos de kits con mayor sensibilidad y especificidad, de tal manera que proporcionen datos con más precisión y así poder instaurar medidas sanitarias correctas para evitar las consecuencias negativas que pudiera generar el ingreso de esta importante enfermedad en explotaciones avícolas, teniendo en cuenta el carácter intensivo que la producción de aves ha adquirido en Paraguay.

Agradecimientos. A la Prof. Dra. María Liz Faccioli Ayala, Prof. Dra. María Goretti Silva, Dr. Walter Daniel Mereles Cáceres, Dr. José Rodrigo Torres Aldama, técnicos del Laboratorio de Diagnóstico de Enfermedades de las Aves y de la División Avicultura del Departamento de Producción Animal, Facultad de Ciencias Veterinarias, Universidad Nacional de Asunción.

\section{REFERENCIAS}

1. Back A. 2004. Manual de doenças de aves, Coluna do Saber, Brazil, 220 p.

2. Calnek B. 2006. Enfermedades de las aves, Manual Moderno, México, 1147 p.

3. Castañeda R, Robin OJ, Morales HJ. 2015. Determinación del catabolismo de los anticuerpos maternos y su interacción con diferentes planes vacunales para la enfermedad de Gumboro en pollos de engorde. Universidad Nacional de Colombia (Bogotá). http://www.bdigital.unal. edu.co/21415/1/17797-57094-1-PB.pdf

4. Castells M, Augustinski S, Ponsa F. 2013. Evaluación zootécnica de dos vacunas intermedias contra la enfermedad de Gumboro en pollos de engorde. 50 Congr. Cientif. Avicultura. http://www.wpsa-aeca.com/aeca_imgs_docs/ castells.pdf

5. Corva S, Silvestrini M, Antonini A. 2010. Manual de Bioestadistica Veterinaria, Ed. Paideia, Buenos Aires, 246 p.

6. da $\operatorname{Re}$ M. 2012. Estudio comparativo de los efectos inmunológicos (niveles de anticuerpos) de vacunaciones realizadas en pollitos parrilleros en planta de incubación y vacunaciones realizadas a campo contra la enfermedad de Gumboro. Tesis Doctoral en Ciencias Veterinarias, Fac. Cs. Vet., Univ. Nac. Asunción, 57 p.

7. Idexx Laboratories. 2009. Kit para la detección de anticuerpos frente al virus de la enfermedad de Gumboro, Publ. Westbrook, Maine, USA, 24 p.

8. Le Gros F. 2008. Evaluación de la respuesta inmune en pollos de engorde y pollitas con dos kits de ELISA después de la vacunación in ovo o días de edad, con vectorizada HVT+IBD Vaxxitek (Informe Merial), Barcelona, 8 p.

9. López MA et al. 2007. Dinámica de anticuerpos pasivos contra el virus de la enfermedad de Gumboro en pollos pesados. Rev Cubana Ciencia Avícola 31: 31-35.

10. Lukert P, Saif Y. 2003. Infectious bursal disease, $11^{\circ} \mathrm{ed}$., Iowa State University Press, Iowa (USA), 174 p.

11. Montiel A. 2004. Interacciones entre agentes inmunosupresores: anemia infecciosa aviar, Gumboro y Marek. II Seminario Internacional Amevea (Lima, Perú). Citado por Rev Inv Vet Perú 2010: 21 (2): 210-218.

12. Reyna D. 2003. Evaluación de la respuesta inmune contra la enfermedad infecciosa de la bolsa de Fabricio-Gumboro mediante la prueba de seroneutralización en cultivo celular. Tesis, Universidad de San Carlos, Facultad de Medicina Veterinaria y Zootecnia, Guatemala, 86 p.

13. Rosales G. 2000. Control actual de la enfermedad infecciosa de la bursa. Memorias XI Seminario Internacional de Enfermedad Aviar, Georgia, USA, p. 468-481.

14. SENACSA 2014. Estadística Pecuaria. Public. Servicio Nacional de Calidad y Salud Animal. Asunción, Paraguay, $82 \mathrm{p}$.

15. van den Berg T. 2000. Acute infectious bursal disease in poultry: a review. Avian Pathol 29: 175-194. 